\title{
UM ESCORÇO DA RACIONALIDADE LIMITADA NAS TEORIAS EVOLUCIONISTA E DOS CUSTOS DE TRANSAÇÃO: PONTOS POTENCIAIS DE CONVERGÊNCIA
}

\author{
Everton de Souza Coelho \\ Professor Assistente da Universidade Federal de Alagoas. \\ Valber Gregory Barbosa Costa Bezerra Santos \\ Economista do Tribunal de Justiça do Estado de Alagoas. \\ Felippe Rocha Presado Menezes de Barros \\ Professor Auxiliar Substituto da Universidade Federal de Alagoas.
}

\begin{abstract}
Resumo - Este artigo, além de levantar as questões fundamentais da Teoria Evolucionista (TE) e da Teoria dos Custos de Transação (TCT), procura identificar pontos potenciais de convergência entre elas. Dessa forma, constata-se que algumas possíveis ligações se dão através da racionalidade utilizada em ambas, dos mecanismos desenvolvidos para reduzir a incerteza, da diminuição dos custos de transação oriunda do desenvolvimento de competências e a partir do conceito de transformação fundamental da TCT, que pode abrir espaço para a inserção do aprendizado, como fonte de explicação da vantagem adquirida pela firma vencedora do processo licitatório. Além disto, o texto conclui, mais especificamente, que são duas as contribuições da racionalidade limitada, a compreensão do contrato como uma forma incompleta de informação e como um ato em que as partes têm que se precaver para que a outra cumpra o contratado.
\end{abstract}

Palavras Chave: Teoria Evolucionista; Custos de Transação; Racionalidade Limitada.

\section{AN EXCESS OF LIMITED RATIONALITY IN EVOLUTIONARY THEORIES AND TRANSACTION COSTS: POTENTIAL CONVERGENCE POINTS}

\begin{abstract}
This article also raises the fundamental questions of Evolutionary Theory (ET) and Transaction Cost Theory (TCT), seeks to identify potential points of convergence between them. Thus, it appears that some possible connections can give through the rationale used in both the developed mechanisms to reduce uncertainty, lower transaction costs arising from the development of skills, and from the concept of fundamental transformation of TCT, which can make room for the inclusion of learning as a source of explanation of the advantage gained by the winning firm bidding process. Moreover, the text concludes, more specifically, that there are two contributions of bounded rationality, understanding the contract as an incomplete form of information and as an act in which the parties have to beware that the contractor complies with the other.
\end{abstract}

Keywords: Evolutionary Theory; Transaction Costs; Limited Rationality.

\section{INTRODUÇÃO}

O presente artigo tem por escopo estudar os pontos de convergência entre a Teoria Evolucionista (TE) e a Teoria dos Custos de Transação (TCT). O espeque da similitude resta nos conceitos de envoltos na tomada de decisão no homoeconomicus, seja este definido como um ator diante de um "conjunto de normas sociais como um produto das interações estratégicas da instrumentalidade racional" (ANDERSON, 2000, p. 171), seja na TE, que recupera conceitos de evolução biológicos ou culturais para caracterizar este comportamento ou ainda mesmo diante de uma racionalidade "social" ou "cultural" da qual a volição humana toma parte como fomentador 
da alteração de uma realidade posta. Em que pese ter se iniciado com um estudo mais conceitual que matemático (AUMANN, 1997, p. 3), a inteligência do conceito de racionalidade limitada, cuja existência dá elo às teorias econômicas acerca da forma pela qual o homem econômico percebe, reconhece e age no mundo, o avanço técnico deu ao conceito uma carga de racionalidade computacional, isto é, de automação cognitiva diante de alterações psíquicas em relação à percepção do mundo pelo homem. Nesta senda, o artigo visa a perceber o caminho que a teoria da racionalidade limitada traça no bojo da TE e TCT como meio de ligação entre elas.

A teoria da racionalidade limitada veio à baila como uma tentativa de demonstrar que os atores econômicos não se deparam apenas com uma propensão a maximizar uma função utilidade. Tal ideia influencia diretamente o conceito de empresa e, de forma corolário, a teoria da firma, visto que a oferta responde a ânimos da demanda. Sobre isto, bem aponta o próprio Simon (1986, p. 209), ao explicar que a suposição de que os agentes econômicos maximizam sua utilidade esperada (racionalidade econômica) oferece apenas uma pequena parcela das premissas econômicas. A TE, ou neoschumpeteriana, em seus fundamentos econômicos, buscou inspiração na teoria Darwiniana para explicar diversos problemas econômicos relacionados às firmas, objetivando identificar o porquê de muitas delas não conseguirem sobreviver no mercado. Dentro do marco deste referencial teórico, as firmas seriam comparadas às espécies, o meio ambiente e ao mercado. A interação entre o mercado e as firmas fará com que somente as firmas mais bem adaptadas consigam sobreviver às tribulações e desajustes verificados no mercado. Dessa forma, trata-se de uma abordagem dinâmica. A TCT, inicialmente desenvolvida por Coase, aprimorada com as contribuições de Williamson (1991), apresenta elementos como: especificidade de ativos, frequência da transação e incerteza, procurando vinculá-los a uma estrutura de governança adequada às características desses atributos. Em outras palavras, dependendo do grau de ativos específicos (alto), frequência de realização (alta) das transações e do nível (elevado) de incerteza, a opção pela estrutura de governança de mercado passa a ser menos viável em comparação com a utilização da estrutura híbrida e da hierárquica (que é mais viável com maiores níveis de incerteza, frequência e especificidade de ativos). Todavia, esta possui um enfoque baseado na estática comparativa.

Pelo fato de ambas as teorias utilizarem pontos de partida diferenciados para analisarem o comportamento das firmas, estas acabam divergindo em vários aspectos, obscurecendo algumas características semelhantes presentes nas duas. Isto torna difícil a visualização de aspectos que podem ter um sentido comum nas teorias, mesmo sem terem sidos desenvolvidos com este intuito. Dando conformidade ao artigo, este está dividido em mais 5 seções além desta introdução e da conclusão. O primeiro capítulo traz uma explanação acerca da racionalidade limitada no seu bojo, ou seja, na teoria de Simon (1955). A segunda seção explica a 
aplicabilidade desta teoria nos estudos da TCT. A terceira, por sua vez, procura delinear com mais ênfase a TCT. A quarta se encarrega de fazer uma revisão da Teoria Evolucionista. O quinto perquire os pontos de convergência entre a TCT e a TE diante do entendimento de racionalidade limitada. A quarta, por sua vez, procura identificar alguns pontos potenciais de convergência entre as duas teorias tratadas neste trabalho.

\section{A RACIONALIDADE LIMITADA (BOUNDED RACIONALITY) EM HERBERT A. SIMON $^{1}$}

Para Simon (apud BARROS, 2010, p. 457) racionalidade é a relação de conformidade (eficácia) entre fins pré-estabelecidos e os meios para alcança-los. Ainda segundo Simon, a especificação dos fins é uma questão de valor estando, deste modo, além do alcance dos fins da ciência. Há, entretanto, necessidade (possibilidade) de se estudar a relação entre os meios e os fins, já que se trata de uma questão de fato. Analisar a conformidade destes dois pontos envolve, segundo Gustavo Barros (2010, p. 457), ao menos três passos: a listagem de todos os comportamentos alternativos possíveis; a determinação de todas as consequências que seguem, no futuro, a adoção de cada uma dessas alternativas (dadas em uma distribuição de probabilidade) e, finalmente, a comparação entre estas alternativas, que devem ser avaliadas em um conjunto de consequências que segue cada uma delas de acordo com fins pré-estabelecidos.

Segundo Koblitz (2008, p. 279), a contribuição de Simon deu-se por demonstrar que o princípio da racionalidade limitada reconhece, em primeiro lugar, o caráter subjetivo da racionalidade; o comportamento racional tem que ser definido com referência às premissas factuais (crenças) e de valores (preferências), que constituem o "modelo subjetivo" da situação em face do agente a racionalidade é subjetiva, ou seja, os limites cognitivos do agente propõe que uma das características centrais do modelo é que ele tem que ser compatível com as limitações informacionais e computacionais do agente (limites humanos, incluindo o estado da tecnologia de processamento de informação). Para Hillmann (1970, p. 150), a contribuição de Simon é que "através de suas hipóteses é possível abordar problemas contemporâneos tais como os relativos à organização administrativa, à investidura de autoridade, à centralização e descentralização, à dicotomia entre a política e a administração etc.” Para Estrada (2010, p. 16) a contribuição genuína de Simon foi o entender sobre o processo de decisão das organizações integradas em um processo de evolução de aprendizagem.

\footnotetext{
${ }^{1}$ Primeiramente, há de se pontuar que os conceitos adotados serão os da obra de Herbert A. Simon, não querendo dizer, com isto, que são inaplicáveis os termos adotados por autores intérpretes em outras situações (NELSON e WINTER, 1982; MARCH, 1994 apud KOBLITZ, 2008).
} 


\section{FALHAS DO MODELO CLÁSSICO}

Simon (1955) enxerga problemas na construção da teoria neoclássica de comportamento. Na realidade, é o que corresponderia ao problema da racionalidade substantiva de sua teoria. Neste contexto, percebe que há falhas com relação à consistência interna das preferências e crenças dos agentes, no que tange o conhecimento e consideração das alternativas viáveis aos agentes e, finalmente, quando da análise das informações sobre a relação entre alternativas e consequências. $O$ problema da consistência interna das preferências dá-se pela violação constante do pré-requisito da transitividade da escolha do agente para que haja uma maximização. Para ser mais específico "a transitividade é facilmente violada quando as consequências que os agentes precisam ordenar possuem atributos diferentes de valor" (KOBLITZ, 2008, p. 259). Segundo o autor retrocitado, a violação da hipótese da transitividade é corrente em estudos empíricos.

Sobre este ponto, Herbert A. Simon aponta ao menos três situações em que a incomensurabilidade há de ser um fator importante: primeiro, casos de incerteza; casos de escolha feita por diversos entes ao mesmo tempo; terceiro, casos em que a escolha doa gente envolve ganhos baseados em uma dimensão e perdas baseadas em outro ponto de partida (SIMON apud KOBLITZ, 2008, p. 259). Passo contínuo, urge discorrer sobre o problema da avaliação de todas as alternativas dadas. Simon critica este sopeso total quando da escolha do agente, visto que há uma distância enorme entre os acontecimentos reais e o pensamento formal; segue-se que o autor considera haver uma situação em que o agente econômico não se defronta com uma situação dada sem se observar o porquê de o agente ter escolhido aquela cesta.Por fim, há um grave problema no grau de informação sobre a relação entre alternativas e consequências. Segundo Koblitz (2008, p. 263), a relação entre alternativas e consequências não permite que, quando da escolha de cestas completamente diferentes, haja a escolha da cesta de fato desejada. Enfim, o que se pontua é que os agentes possuem mais aspectos subjetivos dentro da análise da escolha. Rubinstein (2003, p. 188) traz à baila outra acepção das críticas de Simon quanto à racionalidade substantiva da teoria neoclássica. Enxerga aquele autor que Simon fez ao menos três críticas aos modelos, que seriam

\footnotetext{
1. The models discussed here originate from an "armchair position" and lack any empirical support, except for some reference to the experiments by Tversky and Kahneman.

2. I ignore the huge body of literature, mainly in psychology and artifcialintelligence, that has succeeded in building models that human behavior quite well.

3. Economics does not need more models. It should aim toward the discovery of principles to explain the many phenomena we observe empirically.
}

Ainda, há que se explicar o conceito de racionalidade substantiva e racionalidade procedural, que serão tratados a seguir. 


\section{A CONTRIBUIÇÃO DA RACIONALIDADE LIMITADA PARA A TEORIA DOS CUSTOS DE TRANSAÇÃO}

Ao iniciar seus comentários acerca da contribuição da teoria da racionalidade limitada na TCT, Oliver E. Williamson (1989, p. 138) explica que o agente contratante (contractingman) se distingue da concepção ortodoxa de agente maximizador pelo menos em dois aspectos. $\mathrm{O}$ primeiro deles seria a condição da racionalidade limitada que, conforme veremos, faz com que os contratos sejam celebrados tendo em vista o futuro e a confiabilidade do previsto. $\mathrm{O}$ segundo diz respeito a uma condição filosoficamente mais egoísta: o agente contratante do ponto de vista da racionalidade limitada se interessa mais pelos seus próprios problemas do que o agente maximizador da teoria neoclássica, disposto no conceito clássico da teoria da firma. Para Williamson (1989, pp. 138-139) a racionalidade limitada e o oportunismo servem para relembrar quão importante é distinguirem-se modos de contrato factíveis e inviáveis. Assim, quando se está diante de contratos muito complexos ou muito ingênuos, há de se excluí-los como alternativas viáveis. Neste contexto, pode-se dizer que dois pontos são cruciais ao se determinar um contrato: a incompletude contratual e o contrato como uma forma de promessa.

A incompletude contratual diz respeito ao alcance do conhecimento dos agentes contratantes. Williamson (1989, p. 139) afirma que todos os contratos viáveis são, por si mesmos, incompletos, pois a condição de racionalidade limitada faz com que os agentes contratantes, no bojo da decisão, saibam que é impossível prever o futuro, tendo, então, que se armar com ferramentas que possibilitem uma possível defesa contra imprevistos. Ainda sobre o assunto, o autor diz que, neste contexto, as instituições desempenham um papel central na economia dos custos de transação, haja vista seu papel preponderante nos acertos diluídos nos contratos. Os agentes deixam de apenas se aperceberem do passado (o homemconsumidor neoclássico maximizador de utilidade o faz) para se preocupar com os termos futuros do contrato. Segundo Williamson (1989, p. 140), os contratos também vão levar em conta o oportunismo observado de cada agente contratante, destoando também do conceito clássico de consumidor/produtor. Segundo aquele autor, se os agentes são dados ao oportunismo, os esforços ex ante de se aperceber da confiança vão se esfacelando. Criamse, pois, práticas institucionais para salvaguardar as partes contratantes do oportunismo.

Enfim, as transações (e o crescimento da firma, destarte) passam a sopesar as ferramentas de combate ao oportunismo das partes (visto que agora há de se considerar o cumprimento das promessas ali pontuadas). Assim, custos referentes a estas ferramentas de salvaguarda também definem os movimentos de contratos entre as firmas e acabam por nortear o padrão de crescimento da indústria, levando, também, à criação e/ou fortalecimento de instituições que visem a dar sopeso aos pactos celebrados. Factualmente, pode-se dizer que as firmas vão utilizar das diversas formas de proteção ao 
contratar, tal como o aumento de burocracia, de condições contratuais e de acionamento das instituições públicas (a exemplo da prestação jurisdicional) como forma de se proteger do imprevisto.

\section{TEORIA DOS CUSTOS DE TRANSAÇÃO}

Faz-se necessária uma explanação dos pontos principais da teoria que ficou conhecida como dos Custos de Transação e sua contribuição no estudo da determinação do crescimento da firma. A TCT demonstra que a organização das firmas é importante para se entender as atividades econômicas. $\mathrm{O}$ estudo das peculiaridades das formas de organização pode trazer explicação para o sucesso ou para o fracasso os mesmos processos de ajustamento exigidos pelo ambiente econômico. Segundo Oliver E. Williamson (1985, p. 139), a TCT "assign transactions (which differ in their attributes) to governance structures (the adaptive capacities and associated costs of which differ) in a discriminating (mainly transaction cost economizing) way". Neste context, pode-se afirmar que o ponto central da TCT é o conjunto de características das transações efetivadas, que passam a ser vistas como determinantes da forma de organização da produção do bem ou do serviço envolvido. Ainda nos dizeres de Williamson (1985, p. 17), as relações de troca (ou seja, a transação de um bem ou serviço entre interfaces separáveis) no ambiente capitalista são passíveis de exames pelo TCT. Assim, a eficiência dos contratos firmados é o que determina a organização industrial.

As transações econômicas passam, pois, a ocorrer por duas vias: ou pela compra direta no mercado ou pela transação direta com os agentes. Assim, basicamente, a estruturas das empresas dar-se-ia pelo custo inerente de ir buscar no mercado o necessário ou pela compra direta do agente (o que pode ser interpretado, por exemplo, como verticalização da produção). Ademais, é importante lembrar que estes custos dão-se tanto antes do fechamento do contrato quanto depois (custos ex-ante e ex-post). Os termos ex post serão discutidos na próxima seção. Dentro deste conceito, podemos dizer que temos parâmetros a serem adotados antes dos contratos e outros a serem sopesados como de impacto posterior (e levados a cabo no momento da celebração do contrato). Sobre os parâmetros ex ante, Williamson (1985, p. 17), diz que se mostram em três aspectos: i) o direito de usar o ativo; ii) o direito de apropriação dos seus rendimentos; e iii) o direito de mudar a forma do objeto negociado, sua substância ou emprego.

Pessali \& Fernández (2001, p. 109), ao discutir a cooperação e as características comportamentais dos agentes segundo a TCT asseveram que esta teoria considera o oportunismo dos agentes contratantes como um dos principais aspectos considerados pelas firmas na sua tomada de decisão, no que se refere aos seus limites. Assim, a instabilidade do futuro e o receio da não confiança fazem com que as firmas moldem suas políticas de incorporação de atividades e de outras firmas ou da dependência de mercados com vistas a

$\begin{array}{lllll}\text { REVISTA ECONOMIA POLÍTICA DO DESENVOLVIMENTO } & \text { Maceió - AL } & \text { V.2 N.3. } & \text { JUNHO/2015 } & \text { P.1-24 Página-6 }\end{array}$


preservar seu patrimônio desta instabilidade. Este trato, afirmam aqueles autores, extremo ao oportunismo faz com que a TCT demonstre certo fraquejo quando, por exemplo, não consegue explicar, via comportamento lastreado em racionalidade limitada e oportunismo dos agentes contratantes, alguns outros processos importantes da firma, como a inovação. Milan Zafirovski (2003), por outro lado, pontua,

Rational choice theorists typically make suggestions and claims for a single, unified model rather than many different models of human behavior. In particular, the claim is made that one cannot have two or more different models of the same actor and therefore of the identical human behavior, but rather one - and this is the model of rational choice. However, the question arises as to whether rational choice is really the only or at least the best unified model or general theory of social action. Alternatively, the question can be rephrased to the effect of whether theories of non-rational behavior can also represent a unified and perhaps more adequate model of social action than their rational counterparts.

A Teoria dos Custos de Transação (TCT) faz parte da escola de pensamento novoinstitucionalista e foi desenvolvida a partir das contribuições de Ronald Coase em seu artigo de 1937, intitulado "The Nature of the Firm". A partir daí, diversos autores se despertaram para a pesquisa nessa área, com destaque para Oliver E. Williamson ${ }^{2}$, e a economia dos custos de transação foi disseminada.Uma das críticas à teoria neoclássica da firma reside no fato de os mercados não conseguirem exercer a coordenação necessária e as firmas buscarem a mesma internamente (TIGRE, 1998). Desse modo, com uma ênfase nos preços relativos como forma de conduzir a economia ao equilíbrio, destaque para o indivíduo ao invés da organização e um papel passivo dado as firmas pela teoria neoclássica, a economia dos custos de transação procurou introduzir em sua análise aspectos mais realísticos, concedendo um papel mais ativo para afirma, que na teoria neoclássica se limitava ao ajuste de preços relativos.Uma das premissas que levaram ao desdobramento da TCT foi a busca da explicação para a existência da firma. A resposta encontrada foi que o surgimento de uma firma estaria vinculado à motivação de reduzir os custos de transação (BRONZO, M.; HONÓRIO, L., 2005).

Os custos de transação podem ocorrer ex-ante ou ex-post. Os custos ex-ante se referem aos custos de elaborar e salvaguardar um acordo, já os custos ex-post são aqueles relacionados ao não cumprimento ou a desvios de um contrato. Atrasos, omissões e erros são exemplos típicos de fatores geradores de custos desse tipo. As salvaguardas desempenham um papel fundamental na TCT, pois as mesmas são realizadas na tentativa de reduzir os riscos numa relação contratual; são uma espécie de segurança adicional para que a transação seja efetuada evitando possíveis prejuízos.Penalidades e redução no incentivo ao oportunismo são formas que as salvaguardas podem assumir.A abordagem da economia dos custos de transação procura enfatizar o estabelecimento de contratos como forma de proteger as

\footnotetext{
${ }^{2}$ Sua contribuição teórica é utilizada como uma base para o desenvolvimento desta parte do trabalho.
}

$\begin{array}{llllll}\text { REVISTA ECONOMIA POLÍTICA DO DESENVOLVIMENTO } & \text { Maceió - AL } & \text { V.2 N.3. } & \text { JUNHO/2015 } & \text { P.1-24 } & \text { Página-7 }\end{array}$


transações de condutas desviantes. Estes são firmados especificando a quantidade, qualidade, duração, preços, especificidade de ativos e salvaguardas. Sua definição é um acordo entre ofertante e demandante onde são estabelecidos os termos das transações.

O conceito de estrutura de governança inter-firma ou intra-firmas e refere ao aparato institucional ao qual uma transação é realizada. Ela pode ser de três tipos: governança de mercado, híbrida e hierárquica. A estrutura de governança representa uma forma organizacional. De acordo com os atributos que caracterizam uma determinada transação existirá uma forma de governança adequada.O termo arranjo institucional é sinônimo do conceito de estrutura de governança. $\mathrm{O}$ ambiente institucional se refere às regras legais, sociais e políticas que a atividade econômica se assenta.Numa estrutura de governança de mercado existe um grande número de compradores e vendedores; a identidade das partes não importa, tem-se a preservação da autonomia, a especificidade de ativos é tida como desprezível e o mecanismo de ajuste de preços funciona satisfatoriamente. Os produtos transacionados são padronizados, o que facilita a troca de parceiros quando uma das partes fornece um produto com qualidade inferior. Na governança de mercado, o ambiente vivenciado é o da competição.

Nas estruturas híbridas a identidade das partes importa e existe a preservação da autonomia entre as partes. Todavia, os contratos tendem a ser de longo-prazo onde existe a necessidade de se prover salvaguardas. Estas seriam estruturas intermediárias entre as estruturas de mercado e hierárquica. Neste caso, o grau de especificidade de ativos presente, não justifica a integração vertical e nem a busca no mercado, assim, busca-se um mix entre mercado e hierarquia.A estrutura hierárquica corresponde a internalização dos diversos estágios da cadeia produtiva na firma, o que faz com que sejam eliminadas as necessidades de transações com outras firmas. Quando se aumenta a especificidade de ativos na firma, a opção pela integração vertical se torna fundamental para que seja possível diminuir os custos de transação incorridos, pois comportamentos desviantes podem ser evidenciados. Algumas das vantagens dessa estrutura são: que ela evita conflitos contratuais, incentiva comportamentos cooperativos e pune comportamentos oportunistas. As desvantagens são que ela pode aumentar os custos burocráticos, isto é, custos causados por disputas internas buscando mérito ou pela perseguição de metas individuais em contraposição às metas organizacionais e coletivas (Lages, 2003).

A abordagem da economia dos custos de transação vai definir que a organização da atividade econômica, na tentativa de garantir a fluidez do sistema econômico por meio do ordenamento privado será mais eficiente do que a busca da resolução de problemas via cortes judiciais. Daí mais uma vez o destaque para importância do contrato para evitar o surgimento de possíveis contingências e problemas. Williamson define três tipos de 
racionalidade. A racionalidade substantiva (racionalidade forte), a racionalidade limitada (semi-forte) e a racionalidade orgânica (fraca).

[...] The first or strongest form contemplates maximizing. This is the orientation of neoclassical economics in which firms are reduced to production functions, consumers are characterized as utility function, institutions are taken as given, and optimizing is ubiquitous.[...]The occasion to study alternative means of contracting would vanish if comprehensive intertemporal trading were feasible.(WILLIAMSON, 1984, p. 56).

A racionalidade substantiva é aquela característica da economia neoclássica, onde os indivíduos são caracterizados por funções de utilidade, as firmas por funções de produção. Nesta racionalidade, os agentes são capazes de processar a informação disponível e maximizar seus objetivos. Trata-se de uma racionalidade onde os indivíduos aproveitam de toda a informação presente no ambiente e otimizam suas respectivas funções (utilidade - consumidores e lucro firma). Prevalecendo esta racionalidade, a importância da abordagem contratual desapareceria se o comércio intertemporal fosse possível. A TCT utiliza a racionalidade limitada ${ }^{3}$ como um dos pressupostos comportamentais de sua abordagem. Esta implica que os agentes são racionais, porém possuem limitações em suas capacidades cognitivas. Dessa forma, devido às dificuldades que os indivíduos apresentam em captar as informações existirão brechas para atitudes oportunistas. Os contratos seriam incompletos, pois como os agentes são racionalmente limitados, os mesmos não conseguiriam evitar todas as possíveis contingências surgidas num negócio. Nesse contexto, as decisões passam de ótimas para soluções ditas satisfatórias.

A racionalidade orgânica trabalha com processos evolucionários intra-firma e inter-firma seguindo a linha de Alchian, Nelson e Winter, além de contemplar aspectos relacionados às instituições de moeda, mercados, direitos de propriedades, leis, vistos como um processo, pela escola austríaca.O fato de que os indivíduos apresentam racionalidade limitada para a TCT, e os contratos são incompletos, abre a possibilidade para condutas oportunistas, isto é, condutas que levam a busca pelo interesse próprio, mesmo que prejudique a outrem. Williamson desenvolve uma classificação do oportunismo em três grupos: forma forte, semiforte e oportunismo nulo ou obediência. A forma forte ou oportunismo de primeiro grau, Williamson (1984) define como a busca do autointeresse com astúcia. Ela inclui furtos, traição, fraude, entre outras formas latentes. O oportunismo de primeiro grau também envolve formas sutis, não se limitando apenas a modos mais explícitos. Esse tipo de oportunismo pode ser manifestado ativamente ou passivamente, ex-ante ou ex-post à realização de um contrato. O oportunismo semiforte é aquele que caracteriza a busca pelo autointeresse de modo menos agudo que no primeiro caso. Este segundo modo de oportunismo é tipicamente neoclássico. Isto porque os termos do negócio são fechados entre os agentes de modo completo, num mundo onde os agentes apresentam racionalidade substantiva e são maximizadores.

\footnotetext{
${ }^{3}$ Conceito desenvolvido por Herbert Simon.
} 
Dessa forma, como as declarações do estado das coisas procedem, as partes realizarão o negócio sem eventuais surpresas, o que caracteriza os agentes como cumpridores de contratos.

A terceira categoria de oportunismo corresponde à forma nula ou a virtude da obediência. Nela, o interesse coletivo se sobrepõe às metas individuais. Uma situação onde os funcionários se identificam com os objetivos da empresa é um exemplo característico onde prevalece à obediência, não havendo espaço para atitudes desviantes (oportunismo nulo). Este modo de oportunismo está mais para uma exceção do que para uma regra geral. O mesmo pode ser motivado por valores morais, culturais, religiosos, patrióticos etc. Pessali (1998) sintetiza a classificação dos três tipos de oportunismo apontados acima, ainda destacando que a forma ao qual a TCT vai se centrar reside na forma forte:

\begin{abstract}
Já o oportunismo é uma característica humana que indica a procura do interesse próprio. Entretanto, é diferente da conceituação ortodoxa do indivíduo racional maximizador, na qual se assume um comportamento explícito (e exclusivo) de egoísmo partindo de cada agente, e que é igualmente conhecido e praticado por todos os demais - ao que WILLIAMSON (1985, p. 47-9) chama de forma semiforte da busca pelo interesse próprio. Williamson ainda se refere à obediência como forma fraca, ou mesmo nula, do egoísmo. Tal forma fraca seria característica de sistemas de gerência de classe extrema ou economias centralmente planejadas em que o interesse próprio se desvanece em prol de um determinado grupo social. Mas a TCT se concentra no que é considerada a forma forte de busca do interesse próprio.” (PESSALI, 1998, p. 26 e 27).
\end{abstract}

De acordo com os atributos inerentes a cada transação, diferentes arranjos institucionais ou estruturas de governança ${ }^{4}$ podem ser estabelecidos. Os atributos que qualificam uma transação são: especificidade de ativos, incerteza e frequência. Conceituando especificidade de ativos, Lages (2003, p. 41) define:

Especificidade de ativo diz respeito aos investimentos que são realizados como suporte para determinada transação, incluindo aqueles associados ao capital intangível. Esses investimentos não podem ser reempregados para usos alternativos ou por usuários alternativos sem alguma perda de valor econômico, diante de um grau de especificidade elevado.

Cabe destacar que quando a especificidade do ativo transacionado é relativamente alta, existe uma perspectiva de continuidade da relação comercial entre as partes, urge a necessidade de salvaguardar a transação, de modo que a especificidade não gere problemas. Neste caso, a tendência é que seja elaborado um contrato de longo-prazo que contenha salvaguardas, pois especificidade de ativo requer vínculos mais apertados entre as partes.Ao contrário de uma feira-livre, a identidade das partes importa nesse tipo de relação comercial.Dependendo do grau de especificidade de ativos, a relação contratual pode se tornar prejudicial em face da presença de atitudes oportunistas. Estas, como se sabe, são oriundas da racionalidade limitada que permite a abertura de brechas contratuais. Diante dessa possibilidade, a integração vertical se

\footnotetext{
${ }^{4}$ Essas estruturas são conhecidas e já foram discutidas anteriormente, são elas: mercado, formas híbridas e hierarquia.
} 
torna uma alternativa viável para se contornar problemas de oportunismo vinculados ao alto grau de especificidade de ativos. Os ativos específicos podem ser divididos em seis modos (WILLIAMSON, 1991, p. 128): a) especificidade física de ativos; b) especificidade de capital humano; c) especificidade locacional; d) especificidades de ativos dedicados; e) especificidade de ativos de marca registrada; f) especificidade de ativo temporal.

A especificidade física de ativos refere-se a ativos moldados para transações específicas, como, v.g., máquinas de uso único, ativos desenhados para serem utilizados no processo de fabricação industrial são exemplos dessa especificidade de ativos. A especificidade de capital humano corresponde às características especiais que os indivíduos vão adquirindo em suas rotinas de trabalho, em processos de learning by doing, por exemplo. Especificidade locacional diz respeito à proximidade nos diversos tipos e estágios da transação importa, pois ela acaba gerando menores custos com transporte, estoque, conservação, etc. Especificidade de ativos dedicados- ocorre, por exemplo, quando se verifica uma expansão de uma planta produtiva em função da demanda de um comprador peculiar.Especificidade de ativos de marca registradaé característico ao caso das franquias, onde o franqueado entra no negócio levando o peso da marca, mas devendo cumprir regras rígidas estabelecidas pelo franqueador. Especificidade de ativo temporal-corresponde a produtos que deveriam ser comercializados rapidamente devido ao problema da perecibilidade. Este é fato comum na produção de gêneros agrícolas.

Para Williamson, existe o risco estatístico (statisticalrisk) e o risco latente do comércio idiossincrático (idiosyncratic trading hazard). $\mathrm{O}$ autor procura enfatizar que a incerteza não é só proveniente da falta de comunicação, mas sim provocada também pela distorção de informações, desvio de condutas, fingimento e estratégias falsamente sinalizadas. Procura-se fugir da crença na inocência dos agentes, para um mundo onde o oportunismo está presente. Na abordagem deste autor, Hazards corresponde à incerteza comportamental que surge devido à presença de contratos incompletos, racionalidade limitada, oportunismo e ativos específicos.A incerteza comportamental, por sua vez, é consequência direta do oportunismo.

O terceiro atributo da transação definido por Williamson é a frequência. Quanto maior for esta, aumenta-se a necessidade de criação de arranjos institucionais formais. A frequência da transação permite a concepção da reputação, esta acaba por influenciar nos outros atributos da transação, podendo haver uma diminuição da incerteza e um aumento da especificidade de ativos, a partir da construção da credibilidade/reputação. Com o aumento da frequência, a solução para salvaguardar a transação pode passar desde um aprofundamento da complexidade do contrato, a uma integração vertical. Quando uma transação ocorre repetidas vezes, uma maior facilidade para a obtenção de informações sobre a outra parte envolvida no negócio é promovida, reduzindo a incerteza e aumentando a confiança na relação, isto é, aumentando a 
reputação. Entretanto, o processo de crescimento da reputação, aliado ao aumento na especificidade de ativos, pode levar a empresa fornecedora a aumentar sua margem de lucro, gerando dependência por parte da firma demandante.

Outro conceito trazido por Williansom é aquele que se refere à transformação fundamental. Esta advém de um processo licitatório. Existe nesse processo uma competição ex-ante e ex-post. Caso mais de um participante da licitação esteja qualificado o resultado pode ser inconclusivo. O monopólio prevalecerá na vigência de um ofertante qualificado. E termos competitivos apenas serão alcançados com a participação de numerosos ofertantes. A disputa inicial corresponde à competição ex-ante. A transformação fundamental ocorre quando investimentos em ativos específicos humanos e físicos são efetuados pelo vencedor do primeiro processo licitatório, gerando vantagens para o mesmo num próximo processo licitatório, que caracterizam benefícios criados ex-post a este processo. Portanto, na presença de investimentos em ativos específicos haverá uma transformação fundamental, passando a vigorar uma forte relação bilateral, sendo introduzidas assimetrias contratuais entre o (s) licitante (s) vencedor (es) e os perdedores.

\section{A ABORDAGEM EVOLUCIONISTA}

Para se diferenciar e conseguir a adaptação necessária para prosseguir no mercado, as firmas competem entre si pela busca de novas oportunidades, novos mercados, novas maneiras de se obter insumos (novas fontes de insumos - mais baratos), novo produto, diferenciação do produto, novo método de produção ou comercialização, tudo isso caracterizando a inovação (SCHUMPETER, 1997). Somente as firmas mais bem adaptadas, isto é, que incorporaram a inovação como característica intrínseca da empresa, conseguirão se manter frente as mudanças no mercado. A inovação dentro da teoria evolucionista é considerada como elemento que garante vantagens as firmas que a alcançaram. Diferentemente da análise neoclássica que é expressamente estática, e em que as firmas buscam sempre a maximização dos lucros através do princípio da racionalidade global, a análise neoschumpeteriana é tida em termos expressamente dinâmicos, ou seja, as variáveis em questão são observadas levando em consideração o tempo. Também estão presentes os conceitos de racionalidade limitada, incerteza e desequilíbrio (CÁRIO, 2008). A partir das inovações o sistema econômico passa por desequilíbrio, o qual pode persistir por algum tempo, dependendo da velocidade de reação dos agentes envolvidos no sistema. De acordo com esta visão, os agentes econômicos apresentam racionalidade processual ${ }^{5}$, fruto das assimetrias de informação e limitadas capacidades cognitivas dos agentes, o que traz junto consigo a questão da incerteza.

\footnotetext{
${ }^{5}$ A teoria evolucionista adotou o conceito de racionalidade processual desenvolvido por Simon (autor que desenvolveu trabalhos na área da racionalidade comportamental). Esta racionalidade deriva da racionalidade limitada, 
Em relação aos resultados que uma inovação pode gerar, existe uma forte convicção de que é um processo repleto de incertezas, isto significa que as inovações podem fracassar ou maturar. Não há como prever os seus resultados, e sempre estão associados altos riscos de se fracassar no projeto inovativo. Também estão presentes elevados custos caso sejam detectados erros que precisam ser corrigidos em caso da necessidade de adaptação da inovação. Todavia, para se minimizar os problemas quanto à incerteza da inovação, as firmas adotam o desenvolvimento do procedimento de rotinas.As rotinas por sua vez, promovem o desenvolvimento de um padrão para a maneira de se conduzir as coisas nas mais diversas áreas da firma, seja de produção, distribuição, venda etc.; ou seja, a partir da prática cotidiana de agir diante das situações as rotinas se autoafirmarão como procedimentos habituais dentro de um referencial que orienta o funcionamento e as atitudes da firma.

Um ponto importante referente às rotinas é de que as mesmas sendo produto das atividades cotidianas das firmas, elas acabam por impedir a cópia por parte de outras empresas das mesmas características apresentadas pela firma que se baseia em procedimentos de rotinas, dado o caráter particular, específico e cumulativo das formas com que a firma conduz suas atividades e negócios. Estes tipos de rotinas possuem as características de serem intrínsecas e embutidas nos recursos humanos da empresa.Está presente na discussão inerente ao procedimento das rotinas, a questão da adequação a uma nova realidade que a firma pode enfrentar. Sugere-se que a partir de uma revisão do contexto vivenciado, a firma pode mudar seus procedimentos de rotina habituais para procedimentos que se adéquam de uma melhor maneira aos novos desafios levantados. No decorrer dessa adequação, a firma pode se utilizar tanto de um procedimento de rotina nunca executado, como pode se apropriar de certas combinações de rotinas anteriormente testadas e utilizadas.

A firma ao se valer de regras e normas de funcionamento pré-definidas está se prevenindo de eventuais desvios de condutas por parte de seus funcionários. A utilização do aparato regulatório da firma é essencial para o bom funcionamento do procedimento das rotinas. Entretanto, isto não garante que as rotinas guiarão as atividades plenamente, visto que podem existir desvios de conduta imperceptíveis por parte dos empregados.É importante frisar que não necessariamente as rotinas estabelecidas serão somente rotinas referendadas de acordo com o aparato regulatório, há também aquelas rotinas que são peculiares dos indivíduos que ao passarem pelas mais diversas situações do cotidiano, desenvolvem certo padrão rotineiro de se fazer as coisas.

Também existem aquelas rotinas referentes à postura de sempre se buscar novas combinações, de introduzir novidades no sistema, mais especificamente, aquelas destinadas

que posteriormente foi ganhando espaço nos trabalhos de Simon, em contraposição desta última. A racionalidade processual, como o próprio nome já diz, incorpora a ideia de processo, pois existe a dificuldade dos agentes em interpretar as informações, como também limitadas capacidades computacionais para processá-las. 
à inovação. Pode-se citar, neste contexto, uma política interna da firma de destinar determinado percentual de gastos em P\&D, o que contribuirá para o desenvolvimento de novas oportunidades. Em suma, existem aquelas rotinas do cotidiano, e aquelas que são rotinas que visam transformações. Em Rocha Neto (2010, p. 07) encontra-se uma consideração referente ao mecanismo de seleção:

\begin{abstract}
A ideia de ambientes seletivos provém da interpretação segundo a qual existem mecanismos de seleção que agem sobre os "genes" (rotinas, processos de busca, ativos e competências) e sobre as "mutações" (inovações). Esses mecanismos agem como um filtro que seleciona entre diferentes evoluções possíveis, ou seja, representa o mecanismo de validação e redirecionamento dos processos e resultados da busca que podem resultar em eliminação ou alteração de tecnologias/estratégias insatisfatórias; sendo constituído por fatores que formam o ambiente seletivo onde a firma atua.
\end{abstract}

O importante a considerar é que o mecanismo de seleção atuará sobre os "genes", entendido como as características tecnológicas da firma, e sobre as mutações tecnológicas, dessa forma, o mecanismo de seleção promoverá a eliminação das firmas menos preparadas, bem como fornecerá indícios de possíveis caminhos mais adequados para as firmas se inclinarem, assegurando sua sobrevivência.Para que a firma consiga sobreviver no mercado é necessário que ela possua uma política de investimento definida, que tenha recursos destinados para $P \& D$, tecnologia competitiva, consiga diversificar, e que tenha uma boa política de preços. A firma que possuir esses atributos (unidades de seleção), ou que utilizá-los de forma mais eficiente do que seus concorrentes, provavelmente passará pela seleção do mercado.

Fazendo uma classificação dos elementos de seleção, podem ser mencionadas seis categorias de elementos. São eles: elementos econômicos da estrutura de mercado, elementos da situação macroeconômica, elementos de natureza político jurídico-institucional, elementos do meio ambiente natural, elementos de caráter social e elementos de caráter cultural (Possas, 1999 apud Rocha Neto, 2010). Em se tratando dos elementos econômicos da estrutura de mercado, definiram-se algumas variáveis que possuem o poder de atuar no processo seletivo do mercado. Características dos insumos disponíveis, a demanda por determinado produto, as preferências dos consumidores, vantagens competitivas, qualificação da mão de obra, concentração e tamanho do mercado, são todos fatores que vão operar promovendo o processo de seleção, de modo que, a firma que conseguir melhor se posicionar em relação ao tratamento dessas variáveis, fará jus à continuação no mercado.Do lado dos elementos da situação macroeconômica, podem-se citar como exemplos: as taxas de juros e de câmbio, nível de utilização da capacidade da indústria, situação financeira do setor público, balanço de pagamentos, todas variáveis que expressam a situação macroeconômica da economia e de seus respectivos setores. Essas variáveis agirão no processo de seleção sinalizando se a situação macroeconômica é favorável para expansão, ou desfavorável, ocorrendo retração. Dessa forma, as empresas que conseguirem captar a dinâmica 
do processo de seleção, favorecendo-se de determinadas condições, estarão mais bem preparadas para enfrentar os desafios que possam surgir.

Os mecanismos de seleção de natureza político jurídico-institucional correspondem às leis e normas que regulam as atividades dos agentes econômicos envolvidos no sistema de produção, podendo favorecer ou reprimir firmas ou setores. Outra categoria de mecanismo de seleção é aquela proveniente do caráter social, que procura identificar características do lado social que interferem no processo seletivo. Identificam-se os níveis educacionais, as relações trabalhistas, riqueza, distribuição da renda, sindicatos de trabalhadores, e as relações sociais interativas entre produtores e os compradores, como sendo atributos da categoria de seleção do caráter social.Elementos do meio ambiente natural atuam no processo seletivo através da criação de certas vantagens para as firmas que se beneficiam de recursos naturais. Eles influenciam como mecanismo de seleção por meio de características hidrográficas, do clima, do solo, dos recursos naturais, do relevo, faixa etária da população e da densidade demográfica.Os elementos de caráter cultural são exemplificados como: de natureza histórica, religiosa, referentes à língua, costumes e hábitos, e valores culturais. Todos podem impactar de maneira decisiva no processo de aceitação de certa mercadoria no contexto cultural e das especificidades regionais, o que incide diretamente sobre os rumos e caminhos percorridos pela firma no sentido de sua conquista de espaço dentro do mercado.

É fundamental para a firma, preservar uma boa relação com os consumidores, tanto no sentido de promover a satisfação dos mesmos com os produtos ou serviços prestados pela firma, como no acompanhamento da aceitabilidade do novo produto introduzido no mercado. Dessa forma, manter uma política de qualidade nos bens ou serviços ofertados pela firma, evitar atrasos na entrega de produtos, cumprir com os prazos estabelecidos nos contratos, estabelecer parcerias, possuir canais de comercialização, etc., são todas maneiras de se aperfeiçoar no sentido de assegurar a sobrevivência da firma diante do processo de seleção do mercado.Um aspecto positivo que o processo de concorrência traz encontra-se em Canuto, Higachi \& Porcile (1999, p. 60):

\footnotetext{
[...] A dinâmica de mercado opera como mecanismo de seleção entre agentes heterogêneos (agindo sobre a competitividade relativa de atores individuais), assim como uma poderosa fonte de incentivos para explorações inovadoras, antes do que como alocadora ótima de recursos. Neste sentido, seu papel é fomentar a coordenação ex post entre agentes heterogêneos, bem como a mudança econômica.
}

Em outras palavras, o processo de concorrência estimulará as firmas, incentivando a busca de novas oportunidades via inovação como forma de garantia para a manutenção das mesmas no mercado. Neste sentido, a inovação atua promovendo disparidades entre as firmas que a alcançaram e as que não inovaram. Basicamente para a teoria evolucionista, as firmas serão tidas como exploradoras de oportunidades inovadoras, e não mais serão vistas 
(de acordo com a abordagem neoclássica) alocadora ótima de recursos. Como a abordagem é dinâmica, nada é definitivo, isto implica que as firmas que estão passando por uma situação financeira complicada, mas que possuem um perfil inovador poderão dar a volta por cima, da mesma forma que algumas, que estando numa situação financeira melhor, poderão retroceder. Outro aspecto importante é que a realização de uma inovação pode proporcionar significativos ganhos futuros para a firma, dado que este fato representa um passo à frente no sentido de se promover uma tecnologia mais eficiente.

Dentro do enfoque evolucionista, os agentes podem se comportar de diversos modos dependendo de determinados contextos específicos (DOSI \& NELSON, 1994). Dessa forma, podem se adaptar as mais variadas situações. A busca pela melhor maneira de se fazer as coisas e inserir novidades no sistema é oriunda da necessidade de adaptação ao ambiente de mercado. Dado essa necessidade de adaptação, os agentes evoluem através do processo de aprendizado e novidades são introduzidas no sistema. Com a descoberta da nova tecnologia, a firma inovadora auferirá maiores lucros, o que fará com que provavelmente a mesma seja imitada (NELSON \& WINTER, 1982). Mesmo que determinada firma não seja a pioneira na descoberta de certa tecnologia, a mesma, dependendo de sua maneira de se adaptar, poderá participar dos ganhos provenientes da inserção da nova tecnologia. Isso, desde que a firma consiga seu espaço no mercado, e que seja mais eficiente que muitas de suas concorrentes.

A firma que aprender a lidar rapidamente com a nova tecnologia, que conseguir evitar o acesso de seus concorrentes a informações importantes sobre a nova tecnologia, isto é, se a evolução tecnológica da firma apresenta pouco efeito transbordamento, ou ainda, se os seus concorrentes são lentos para perceber o novo paradigma tecnológico, provavelmente a firma sairá uma vencedora com considerável ampliação de sua margem de lucro. Todavia, caso a firma aprenda a lidar lentamente com a nova tecnologia, e se a evolução tecnológica da firma apresenta um significativo efeito transbordamento, ou se os seus concorrentes são rápidos o suficiente para acompanhar o novo padrão tecnológico, a firma sairá perdedora, ou seja, haverá forte pressão para que a firma perca espaço no mercado, podendo até ser eliminada, caso não lance mão de uma proposta tecnológica inovadora eficiente para solucionar seus problemas.

Cabe aqui definir o conceito de paradigma tecnológico. Como foi abordado neste trabalho, existe uma forte ligação entre ciência e tecnologia. A P\&D sendo desenvolvida pelas firmas que apresentam esse perfil inovador implicará na obtenção de resultados satisfatórios, gerando as inovações tão essenciais para o crescimento e manutenção da firma dentro do mercado. Dessa forma, cabe a ciência o papel de buscar soluções para os problemas habituais do cotidiano das firmas, isto inclui, a busca de novas soluções e padrões viáveis. Em ciência, a delimitação do problema fornece os elementos essências para se promover uma investigação; definem-se tarefas objetivando a resolução 
dos problemas enfrentados, tendo em vista as perspectivas a cerca dos resultados. Este procedimento de delimitação do problema, investigação, e resolução tendo em vista as perspectivas pré-definidas, é aplicável na solução dos problemas mais gerais e também é para o caso dos problemas tecnológicos. $\mathrm{O}$ conceito de paradigma tecnológico, como sendo um padrão ou modelo desenvolvido para a resolução dos problemas tecnológicos, envolve justamente estes elementos; pois para se propor uma investigação da viabilidade do paradigma é essencial a utilização do arcabouço científico.

É evidente que o estabelecimento de um paradigma tecnológico é fruto de um processo de busca, de uma melhor maneira de se fazer as coisas, de investimentos em pesquisa, e da regularidade na eficiência de se resolver os problemas enfrentados. A instauração de um padrão tecnológico favorece a acumulação de conhecimentos relacionados ao avanço técnico, o que contribui para que as firmas possuidoras desse padrão tecnológico consigam obter vantagens competitivas frente às rivais, dadas as possíveis mudanças complementares associadas a esse padrão.As mudanças que um paradigma tecnológico pode enfrentar são duas. A primeira está relacionada com uma mudança brusca no padrão tecnológico aceitável, neste caso, o antigo paradigma será ultrapassado por um superior. A segunda está associada a mudanças que visam melhorar o padrão tecnológico já estabelecido, ou seja, são mudanças que objetivam a busca pelo aperfeiçoamento do padrão vigente.

Cabe salientar que um paradigma tecnológico está submetido à concorrência de outros paradigmas potenciais, podendo ser superado dependendo do grau de aceitabilidade do padrão alternativo. Dessa forma, num processo de mudança de paradigma tecnológico, o paradigma enfraquecido pode ser revitalizado ou ser superado, também pode ocorrer que um potencial paradigma tecnológico (um terceiro paradigma) seja promovido em virtude de um padrão superior ter sido desenvolvido enquanto que o antigo paradigma tentava se revitalizar, e o segundo tentava superar o primeiro.Com o intuito de minimizar os riscos ligados às incertezas geradas pela busca e implementação de um novo padrão tecnológico, o desenvolvimento de rotinas se torna indispensável. Não resta dúvida que o processo de inovação e a instauração de um novo padrão tecnológico são marcados por incertezas, entretanto, o desenvolvimento de rotinas contribui para obtenção de regularidades que são essenciais para garantir o sucesso do novo paradigma.Antes do estabelecimento de um design dominante, da afirmação de um modo de produção superior, isto é, a definição de um padrão tecnológico ser reconhecido como o mais viável, diagnostica-se que as firmas participantes do mercado em sua maioria são pequenas, e que a entrada de concorrentes é tida como relativamente fácil, refletindo no emprego de uma grande diversidade tecnológica.

No entanto, com a emergência de um paradigma tecnológico, uma tendência de concentração de mercado começa a surgir. Com configuração do novo padrão tecnológico, as firmas que não se adaptarem a nova realidade terão dificuldades para continuar no mercado. 
Essa pressão exercida pela nova tecnologia vigente exigirá certo volume de investimento por parte das firmas, no sentido do alcance do domínio do novo paradigma tecnológico. Dessa forma, surgem barreiras à entrada exigindo um determinado nível de investimento para que as firmas possam conseguir se manter no mercado.

Uma questão importante a destacar está relacionada com a incerteza que o processo de aprendizado da firma acaba gerando no manuseio do padrão tecnológico vigente. Basicamente, têm-se duas incertezas ligadas a este processo. A primeira diz respeito ao caso que se tem uma grande diversidade tecnológica oriunda dos mais variados processos de aprendizado. Neste caso, as incertezas da firma estão ligadas com a direção a ser seguida, isto é, dado que existem diversidades tecnológicas baseadas em diferentes processos de aprendizado, a questão chave é identificar qual seria o padrão mais viável a ser adotado. A segunda incerteza gerada a partir do processo de aprendizado é aquela que está vinculada a possíveis descontinuidades de trajetórias tecnológicas da indústria. Isto significa que a firma ao adotar determinada escolha tecnológica e ao investir seus esforços na opção da escolha estabelecida (isto é, investir no processo de aprendizado dessa tecnologia), dependendo da continuidade ou descontinuidade de sua escolha tecnológica, ela será bem ou mal sucedida.

A teoria evolucionista também menciona a importância da dinâmica de retornos crescentes para as indústrias. Ela sugere que existem inovações que proporcionam através de uma rede de externalidades, benefícios para os consumidores e para as empresas, a exemplo disso, pode-se citar: a telefonia e a internet. Também existem aqueles aspectos, dentro da dinâmica de retornos crescentes, que salientam a criação de um produto que possui a característica de complementaridade de outro produto que foi a priori desenvolvido.

\section{POTENCIAIS PONTOS ${ }^{6}$ DE CONVERGÊNCIA ENTRE AS TEORIAS}

Dosi \& Egidi (1991, p. 152) ${ }^{7}$ definem três vertentes evolucionistas que interpretam a racionalidade de modo diferente desses autores. São desenvolvimentos vinculados à ideia de Friedman, em que sustentam que os indivíduos embora não possuam os instrumentos necessários para o cálculo do ótimo, atuam como $\mathrm{se}^{8}$ os utilizassem.A primeira delas corresponde às contribuições de Alchian e Friedman. Egidi (2008, p. 205) afirma que:

La solución de Friedman y Alchian sugiere que lós indivíduos alcanzaronlos comportamentos racionales a través de um proceso de adaptación evolutiva que no requiere pleno conocimento y conciencia de sus comportamientos. Naturalmente, em tal caso se necesita demostrar que em um proceso evolutivo lós

\footnotetext{
${ }^{6}$ Não se objetiva neste trabalho dizer que os pontos abordados nessa seção são necessariamente iguais segundo as duas teorias, mas sim que existem algumas semelhanças em certos aspectos.

${ }^{7}$ A racionalidade da teoria evolucionista neste trabalho está fundamentada nestes autores.

${ }^{8}$ São as visões conhecidas na literatura econômica como: as if.
} 
comportamientos no apropiados se excluyen selectivamente y que existe la posibilidad de que surjan sólolos comportamentos racionales

Portanto, para esses autores, os agentes atingirão comportamentos racionais a partir do mecanismo de seleção de mercado, que permite que apenas os comportamentos apropriados permaneçam existindo. Neste caso, a seleção de mercado retém os comportamentos racionais, fazendo com que os agentes que adotem tais comportamentos sobrevivam.A segunda vertente defende que os agentes tendem a fazer o melhor uso da informação disponível, entretanto, como existe assimétrica e imperfeita informação, seus conhecimentos acerca do futuro são limitados. Os agentes fariam as escolhas ótimas se estivessem em um ambiente de informação perfeita. Como não estão nesse ambiente, os mercados acabam substituindo em maior ou menor extensão a falência das firmas, promovendo um processo de seleção, onde, os agentes que captarem melhor as informações do mercado, conseguirão sobreviver. Esta é uma abordagem que é representada por Arrow e Hahn. A terceira ${ }^{9}$ contribuição vem de Machlup e Friedman. Eles argumentam que na medida em que as regras presentes no ambiente propiciam variados graus de automaticidade, elas acabam conduzindo os indivíduos para a realização de ações ótimas.Todavia, a racionalidade adotada por Dosi \& Egidi é a racionalidade processual. Esta se deriva da racionalidade limitada, pois reflete os problemas ligados à incerteza, como também a baixa capacidade cognitiva e computacional dos agentes em interpretarem os eventos, caracterizando assim, limitações na racionalidade dos agentes.

$\mathrm{Na}$ teoria dos custos de transação, um dos pressupostos comportamentais é de que a racionalidade dos agentes é limitada. Desse modo, como a racionalidade processual adotada pela teoria evolucionista provém da limitada, e ela foi desenvolvida para cumprir com o mesmo objetivo (explicar a limitação da racionalidade dos agentes e ser uma forma alternativa a racionalidade substantiva - neoclássica), pode-se atestar que as racionalidades em que as duas teorias se apoiam exercem a mesma função e surgiram da mesma preocupação.Outro possível ponto de convergência entre as teorias está vinculado ao fato de ambas terem uma preocupação com a incerteza. Tanto a TCT como a teoria evolucionista buscaram soluções para a redução da incerteza.

Dentro da TCT a solução foi apontada para a estrutura de governança, que corresponde à governança de mercado, híbrida e hierárquica. Na medida em que a incerteza vai aumentando no ambiente, uma estrutura de mercado vigente pode deixar de ser viável devido ao oportunismo e a questão da racionalidade limitada, o que pode levar a firma a um prejuízo considerável. Desse modo, uma estratégia para reduzir a incerteza seria a busca para uma estrutura híbrida ou uma governança hierárquica, que estaria ligada a maiores graus de incerteza.Para a teoria evolucionista éo desenvolvimento de rotinas que atuam no sentido de reduzir a incerteza. Dosi \& Egidi (1991, p. 165) afirmam que:

\footnotetext{
${ }^{9}$ A terceira contribuição pode se sobrepor a segunda contribuição, assim como coincidir com a primeira, quando o mundo estiver num "equilíbrio de seleção". 


\begin{abstract}
In the most general sense, innovation is the process of discovery of new routines. [...] In this interpretation, innovation is an endogenous mechanism of generation of uncertainty in the environment, since each innovation is in act the appearance of a new, unexpected event. At the same time it is a procedure through which the innovator, when successful, solves more efficiently, with greater generality, a particular set of problems, and, hence, through the resulting routines, reduces complexity and procedural uncertainty.
\end{abstract}

Para os autores, a inovação em si é um processo de descoberta de novas rotinas. Com o surgimento de uma inovação, esta carrega consigo a geração de uma incerteza ambiental. Todavia, para a firma inovadora, o estabelecimento e a aprovação de sua descoberta significa para ela a diminuição da incerteza e a garantia de ganhos elevados. Dessa forma, com o desenvolvimento de rotinas é que ocorre a diminuição da incerteza processual. Outro fator que agirá diminuindo a incerteza na teoria evolucionista se refere a bons níveis de conhecimento tácito ${ }^{10} \mathrm{e}$ codificado ${ }^{11}$ (principalmente o primeiro). Isto porque os mesmos surgirão através das rotinas desenvolvidas, sendo que o conhecimento tácito tem a característica de ser de difícil transmissão, o que contribui para a criação de vantagens específicas para a firma que o possuir.As duas teorias, destarte, caracterizam-se pela busca de mecanismos para reduzir a incerteza. Estes mecanismos, contudo, atuam na tentativa de alcançar o mesmo objetivo, seja na TCT como também na teoria evolucionista. O conceito de transformação fundamental desenvolvido por Williamson carrega consigo alguns elementos que podem ser conectados a pontos tratados pela teoria evolucionista.

A questão do aprendizado parece ter espaço para absorção pela TCT a partir do conceito de transformação fundamental (Williamson, 1985, p. 61). Isso porque o estabelecimento de uma relação contratual com um certo agente após uma licitação com diversos concorrentes igualmente capacitados acaba gerando uma relação de dependência bilateral (embora nem sempre na mesma intensidade) em função do conhecimento, da idiossincrasia, ou da "especificidade" desenvolvidos a partir do cumprimento das tarefas estabelecidas (ou mesmo resultando em rotinas ou competências compartilhadas). (FERNÁNDEZ \& PESSALI, 2001, p. 112).

$\mathrm{Na}$ citação descrita acima, os autores procuram destacar que com a criação da definição de transformação fundamental, esta abre espaço para que ocorra o processo de aprendizado característico da teoria evolucionista na TCT. Isto porque a transformação fundamental advém de um processo licitatório, onde o vencedor sairá com vantagens sobre os seus concorrentes em licitações posteriores devido à criação de ativos específicos, conforme exigidos no contrato, e maiores investimentos serão realizados, configurando assim, o surgimento de uma relação de dependência bilateral. A vantagem adquirida pode ser fruto de ações rotineiras ou do desenvolvimento compartilhado de competências, dessa forma, o processo de aprendizado engendrado por alguma (s) dessas iniciativas surge na análise como uma possível fonte de explicação para a criação de competências e vantagens específicas.

\footnotetext{
${ }^{10}$ Envolve experiências e habilidades pessoais.

${ }^{11}$ Pode ser transmitido via manuais, livros, textos, revistas etc.
}

\begin{tabular}{llllll}
\hline REVISTA ECONOMIA POLÍTICA DO DESENVOLVIMENTO & Maceió - AL & V.2 N.3. & JUNHO/2015 & P.1-24 & Página-20
\end{tabular}


Sobretudo, ocorre um link entre a TCT e a teoria evolucionista via transformação fundamental ${ }^{12}$ e criação de especificidade de ativos pelo lado da TCT; e rotinas, competências e aprendizado pelo lado da teoria evolucionista.O quadro (1) traz em síntese os pontos aqui discutidos onde a Teoria dos Custos de Transação e a Teoria Evolucionista apresentam potenciais ligações.

Quadro 1. Potenciais Pontos de Convergência entre as Teorias.

\begin{tabular}{|c|c|c|}
\hline TCT & Teoria Evolucionista & Ligação \\
\hline Racionalidade Limitada. & $\begin{array}{c}\text { Racionalidade } \\
\text { Processual. }\end{array}$ & $\begin{array}{c}\text { Racionalidades originadas com o } \\
\text { objetivo de destacar a ausência de } \\
\text { racionalidade substantiva. }\end{array}$ \\
\hline Estrutura de Governança. & $\begin{array}{c}\text { Rotinas e Conhecimento } \\
\text { Tácito. }\end{array}$ & $\begin{array}{c}\text { Mecanismos desenvolvidos para } \\
\text { reduzir a incerteza. }\end{array}$ \\
\hline $\begin{array}{c}\text { Transformação Fundamental } \\
\text { e Especificidade de Ativos. }\end{array}$ & Rotinas e Aprendizado. & $\begin{array}{c}\text { O conceito de transformação } \\
\text { fundamental pode abrir espaço para } \\
\text { a aplicação do aprendizado na } \\
\text { análise. }\end{array}$ \\
\hline $\begin{array}{c}\text { Diminuição nos Custos de } \\
\text { Transação. }\end{array}$ & $\begin{array}{c}\text { Criação de } \\
\text { Competências. }\end{array}$ & $\begin{array}{c}\text { A criação de competências implica } \\
\text { na redução dos Custos de } \\
\text { Transação. }\end{array}$ \\
\hline
\end{tabular}

Fonte: Elaboração própria.

Um último aspecto a ser tratado se refere à ligação das competências junto à diminuição dos custos de transação. Embora a TCT não lide com uma abordagem dinâmica evolutiva e não desenvolva conceitos vinculados ao aprendizado e criação de competências, ocultando-se instantaneamente as diferenças metodológicas relacionadas à análise estática comparativa (TCT) e a abordagem dinâmica (TE), a ligação entre os dois pontos discutidos se dá intuitivamente. Pois, na medida em que se abre espaço para a criação de competências, estas logo agirão na direção da diminuição dos custos de transação.

\section{CONCLUSÃO}

Várias as conclusões do presente estudo. Conforme disposto durante todo o trabalho, percebese que a ideia de racionalidade limitada deu azo, na realidade, para uma quebra de paradigma pelo afastamento da ideia de agente maximizador objetivo. A partir desta contribuição, foi-se diluindo nas estruturas econômicas a percepção da subjetividade do processo de escolha dos agentes e, corolário a isto, sua influência no processo organização das firmas, visto que estas são, em última instância, geridas por pessoas naturais. Assim, percebe-se que dada a limitação de racionalidade, os agentes econômicos são incapazes de antecipadamente prever e estabelecer medidas corretivas para qualquer evento que possa ocorrer quando da futura realização da transação, de modo que as partes

\footnotetext{
${ }^{12}$ Estas ligações só ganham espaço na discussão a partir do desdobramento do conceito de transformação fundamental.
} 
envolvidas devem levar em conta as dificuldades derivadas da compatibilização das suas condutas futuras e de garantir que os compromissos sejam honrados dentro da continuidade da sua interação.

A principal contribuição da ideia de Simon sobre racionalidade limitada para Williamson e sua TCT é a informação de que os agentes são mais subjetivos do que se pensava, no sentido de que os contratos sempre vão levar em conta a limitação do conhecimento dos agentes contratantes sobre fatos futuros (imprevisíveis), o que torna o mercado um complexo de local de contratos totalmente incompletos do ponto de vista da sapiência sobre seu futuro e do oportunismo dos agentes, que é combatido por cláusulas penais que tentam diminuir a insegurança dos contratantes.

Acerca da diluição do pensamento da racionalidade limitada, embora as duas teorias apresentem abordagens diferentes quanto ao aspecto da eficiência estática (na TCT) e eficiência dinâmica (na Teoria Evolucionista), podem ser listados alguns pontos de possíveis conexões entre elas.O primeiro deles se refere à racionalidade limitada (da TCT) e a racionalidade processual (presente na Teoria Evolucionista), que se vinculam a partir de um objetivo comum em ambas - destacar a ausência de racionalidade substantiva nos agentes.Um segundo ponto de potencial conexão se dá via utilização de uma estrutura de governança adequada (TCT) e a criação de rotinas e presença de conhecimento tácito (pelo lado da TE), como forma de mecanismos desenvolvidos com o intuito de reduzir a incerteza.

Outra possível conexão surge a partir do conceito de transformação fundamental, que permite a criação e aumento da especificidade de ativos da empresa vencedora do processo de licitação, gerando vantagens para a mesma em processos licitatórios posteriores, abrindo espaço para a inserção do aprendizado (elemento da TE) como forma de explicação para a vantagem adquirida. Por fim, uma última ligação visualizada neste trabalho consiste na explicação para a diminuição dos custos de transação através da criação das competências (TE). Lembrando que esta conexão só pode ser estabelecida deixando de lado por um momento as diferenças quanto à análise da estática comparativa de uma, e a análise dinâmica de outra.

Entretanto, as ligações apontadas acima não respondem pelos absolutos pontos de conexões entre as teorias, havendo espaço para a investigação de outros aspectos relacionados à vinculação entre elas. A observação da questão da incerteza utilizada em cada abordagem pode apontar para outras características comuns em ambas. Assim como a tentativa de adequação da TCT para análises de longo-prazo ${ }^{13}$ pode trazer elementos novos para este tipo de pesquisa. Em suma, a TE e a TCT possuem alguns pontos de potencias ligações que trazem consigo a importância do progresso de ambas as análises para a explicação de questões pertinentes ao estudo das firmas, estando presentes na análise, além de questões específicas a cada teoria, algumas preocupações que são similares.

\footnotetext{
${ }^{13}$ A TCT é uma teoria apropriada para o curto-prazo (Fernández \& Pessali, 2001).

\begin{tabular}{lllll}
\hline REVISTA ECONOMIA POLÍTICA DO DESENVOLVIMENTO & Maceió - AL & V.2 N.3. & JUNHO/2015 & P.1-24 Página-22
\end{tabular}
}




\section{REFERÊNCIAS}

ANDERSON, Elizabeth. Beyond Homo Economicus: New developments in theories of Social Norms. Princeton University Press. Philosophy G Public Affairs 29, no. 2, 2000, p. 171-200. Disponível em: http://www-personal.umich.edu/ eandersn/norms.pdf. Acesso em: 10 de fevereiro de 2014.

AUMANN, Robert J. Rationality and bounded rationality. Games and Economic Behavior 21, 2-14, 1997. Disponível em http://www.ma.huji.ac.il/raumann/pdf/Bounded\%20Rationality.pdf. Acesso em 25 de setembro de 2012.

BARROS, Gustavo. Herbert A. Simon and the concept of rationality: Boundaries and procedures. Brazilian Journal of Political Economy, vol 30, no 3 (119), pp 455-472, July-September/2010. Disponível em: http://www.scielo.br/pdf/rep/v30n3/a06v30n3.pdf. Acesso em: 25 de setembro de 2012.

BRONZO, M.; HONÓRIO, L. O Institucionalismo e a Abordagem das Interações Estratégicas da Firma. RAE-eletrônica, v. 4, n. 1, Art. 5, jan./jul. 2005.

CANUTO, O.; HIGACHI, H. \& PORCILE, G. Modelos evolucionistas de crescimento endógeno. Revista de Economia Política, v. 19, n. 4 (76), 1999.

DOSI, G.; EGIDI, M. Substantive and procedural uncertainty: An exploration of economic behaviours in changing environments. Journal of Evolutionary Economics, 1:145-168, 1991.

DOSI, G.; NELSON, R. R. An Introduction to evolutionary theories in economics. Journal of Evolutionary Economics, v. 4, p. 153-172, 1994.

EGIDI, M. De la racionalidad limitada a la economia comportamental. In: LAS NUEVAS ECONOMIAS. MEXICO: FLACSO, p. 189-218, 2008.

ESTRADA, Fernando. Economics and rationality of organizations: an approach to the work of Herbert A. Simon. CIPE, april 2010. Disponível em: http://mpra.ub.unimuenchen.de/21811/1/ECONOMICS_AND_RATIONALITY_april_2010.pdf. Acesso em: 25 de setembro de 2012.

FERnÁNDEZ, R. G.; PESSALI, H. F. Teoria dos Custos de Transação e Abordagens Evolucionistas: Análise e Perspectivas de um Programa Pluralista. Revista de Economia Política, v. 21, n. 2, abril-junho, 2001.

GUIMARÃES, E. A. Acumulação e crescimento da firma. Rio de Janeiro, Zahar, 1982.

HILLMAN, Richard S. A contribuição da análise científica ao estudo da administração: a teoria das decisões. Revista de Administração de Empresas: Rio de Janeiro, 10 (2): 141-156, abr./jun. 1970.

KOBLITZ, Arthur. Simon e a racionalidade limitada. In: Economia e Desenvolvimento, Recife (PE), v. 7, n. 2, 2008.

LAGES, A. M. G. A Relocalização Espacial da Indústria de Calçados de Couro Brasileira na década de 90: Aspectos Teóricos e Empíricos. UFRJ, Tese de doutoramento, 2003.

NELSON, R. R. Why do firms differ, and how does it matter. Strategic Management Journal, v. 12, p. 61-74, 1991.

PEREIRA, J. A. Teoria da firma e analogias biológicas: em busca de uma contribuição teórica para o estudo das empresas transnacionais como agentes da transformação econômica. Disponível em: http://www.pucrs.br/eventos/encontroeconomia/download/mesas/TeoriaDaFirma.pdf. Acesso em: $16 \mathrm{de}$ setembro de 2012. 
PESSALI, H. F. Teoria dos Custos de Transação: Uma Avaliação à Luz de Diferentes Correntes do Pensamento Econômico. UFPR, Dissertação de Mestrado, 1998.

PESSALI, Huáscar Fialho; FERNÁNDEZ, Ramón García. Teoria dos custos de transação e abordagens evolucionistas: análise e perspectivas de um programa de pesquisa pluralista. Revista de Economia Política, v. 21, n. 2 (82), abril-junho, 2001.

ROCHA NETO, R. da.Aabordagem evolucionária por meio dos processos de busca, seleção e rotina confrontados aos conceitos de Simon. 2010. Disponível em: http://www.litzestrategia.com.br/publicacoes/\%5BLITZ\%5D\%20processos_busca.pdf. Acesso em: 15 de setembro de 2012.

RUBINSTEIN, Ariel. Modeling bounded rationality. The MIT Press: Cambridge, 1998. Disponível em: http://arielrubinstein.tau.ac.il/br/br.pdf. Acesso em: 25 de setembro de 2012.

SCHUMPETER, J. A. Teoria do desenvolvimento econômico. São Paulo: Editora Nova Cultural, 1997.

SIMON, H.A behavioral model of rational choice. Quartely Journal of Economics, 69, February, p. 99$118,1955$.

SIMON, Herbert A. Rationality in psychology and economics. The Journal of Business, Vol. 59, No. 4, Part 2: The Behavioral Foundations of Economic Theory. (Oct., 1986), pp. S209-S224.

STIRLING, Wynn C. Satisficing games and decision making: with applications to engineering and computer science. Cambridge University Press: 2003, p. 1-10. Disponível em: http://assets.cambridge.org/97805218/17240/excerpt/9780521817240_excerpt.pdf. Acesso em: 25 de setembro de 2012.

TIGRE, P. B. Inovação e Teorias da Firma em Três Paradigmas. Revista de Economia Contemporânea, n. 3, Jan.-Jun. 1998.

WILLIAMSON, O. E. Comparative economic organization: the analysis of discrete structural alternatives. Administrative Science Quartely, v. 36, p. 269-296, 1991.

WILLIAMSON, O. E. The Economics of Governance: Framework and Implications. Journal of Institutional and Theoretical Economics, 195-223, 1984.

WILLIAMSON, O. E. Transaction cost economics. In: SCHMALENSEE, R.; WILLIG, R.D. Handbook of Industrial Organization, Volume I, Elsevier Science Publishers B.V., 1989, p. 135-182.

WINTER, S.On coase, competence, and the corporation, In: WILLIAMSON, O. E. \& WINTER, S. The nature of firm: origins, evolution, and development. Oxford: Oxford University Press. P. 179-195, 1991.

ZAFIROVSKI, Milan. Human rational behavior and economic rationality. Electronic Journal of Sociology: 2003. Disponível em: http://www.sociology.org/content/vol7.2/02_zafirovski.html. Acesso em: 25 de setembro de 2012. 